\title{
Prolapsed ileocolic intussusception
}

\author{
Ibrahim Ali Ibrahim
}

\begin{abstract}
Purpose This study aimed at presenting our experience with cases of prolapsed intussusception and discussing the line of treatment and the morbidity and mortality.
\end{abstract}

Patients and methods Nine infants aged from 5 to 10 months were diagnosed as prolapsed intussusceptions by clinical examination. All of them were treated by abdominal exploration through a right transverse supraumbilical incision.

Results The mean operative time was $65 \mathrm{~min}$. The intussusceptum was viable in five cases and was gangrenous in four cases. There was ischemic perforation in the colon in two cases. Resection and anastomosis were performed in six cases, sigmoid colostomy was performed in one case, and reduction by milking without resection was performed in three cases. All the patients recovered well.

\section{Conclusion Prolapsed intussusception is a rare} presentation of intussusceptions; its diagnosis is easy but may be misdiagnosed as rectal prolapse. Its only treatment is surgery and it carries a good prognosis. Ann Pediatr Surg 7:76-78 (c) 2011 Annals of Pediatric Surgery

Annals of Pediatric Surgery 2011, 7:76-78

Keywords: intussusception, prolapsed intussusception, ileocolic intussusception

Pediatric Surgery Unit, Assiut University, Egypt

Correspondence to Ibrahim Ali Ibrahim, Pediatric Surgery Unit, General Surgery Department, Faculty of Medicine, Assiut University, Assiut, Egypt

Tel: + 208882290940; fax: + 20882334541; e-mail: dr.ibrahimali@yahoo.com

Received 26 October 2010 Accepted 3 January 2011

\section{Introduction}

Intussusception is one of the most common causes of acute abdomen in early childhood. Depending on the affected bowel part, intussusception may be ileoileal, ileocolic (the most frequent), ileoileocolic, or colocolic [1].

The clinical presentation is characterized by a triad of abdominal pain (usually intermittent, but recurs and becomes stronger), red currant jelly stool, and a palpable mass. The classical triad is present in only $50 \%$ of patients [2]. If left untreated, intussusception can cause severe complications, which include irreversible tissue damage, perforation of the bowel, and prolapse. Prolapsed intussusception is defined as the invagination of an intestinal segment into the adjacent segment to it, with exteriorization of the head of the intussusception through the anus [3].

\section{Patients and methods}

This study included nine patients who presented to our unit with prolapsed intussusception. Four of them were referred to us from other hospitals, and two patients were referred by a pediatrician. They were three boys and six girls. Their ages ranged from 5 to 10 months at diagnosis (Table 1). All patients were diagnosed on clinical bases, by palpating the prolapsed intestine and by inserting a finger circumferentially between the protruding mass and the anal wall (Figs 1 and 2). The length of the prolapsed intussusception ranged from approximately 8 to $15 \mathrm{~cm}$.

All patients were dealt with on emergency bases. After securing an intravenous line and a urethral catheter, resuscitation was started immediately by antishock measures. A blood sample was drawn for cross matching and laboratory investigations (complete blood count, renal function, blood sugar, prothrombin time and concentration, and serum electrolytes).
Table 1 Age and sex

\begin{tabular}{lcc}
\hline & \multicolumn{2}{c}{ Sex } \\
\cline { 2 - 3 } Age (months) & Male & Female \\
\hline $5-6$ & 2 & 1 \\
$7-9$ & 1 & 4 \\
$\uparrow 9$ & - & 1 \\
\hline
\end{tabular}

Fig. 1

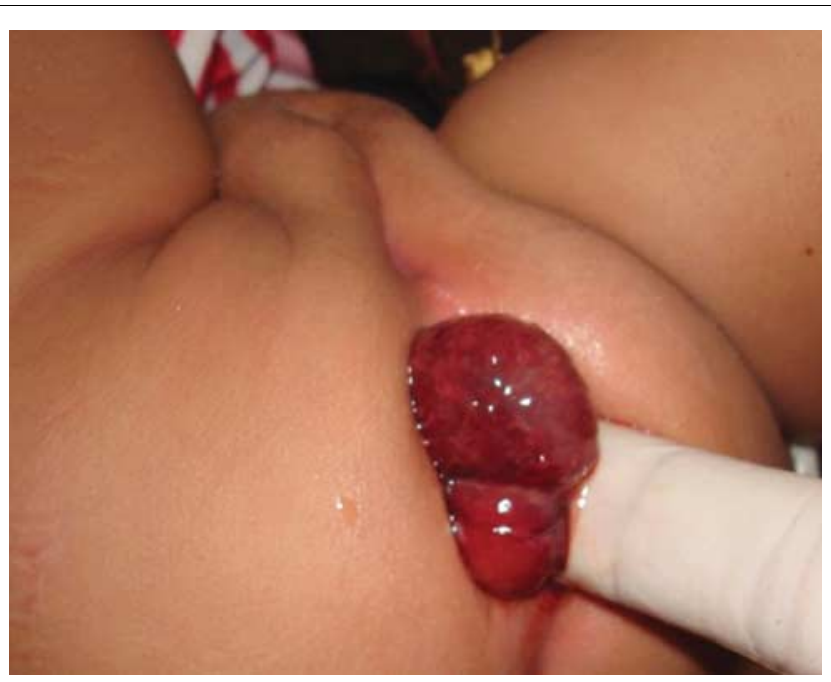

A finger inserted between the prolapsed mass and the anal canal.

After resuscitation and correction of electrolyte imbalance, usually within few hours, the patient was taken to the operation theater, and the abdomen was explored through a right transverse supraumbilical incision. 
Fig. 2

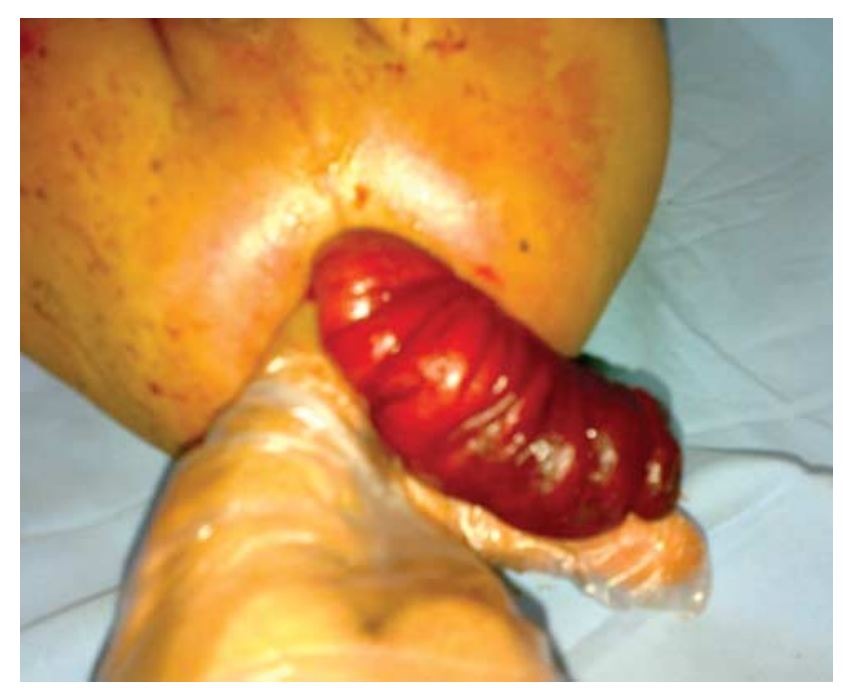

A finger inserted between the prolapsed mass and the anal canal.

\section{Results}

The mean operative time was 65 min. Manual reduction of the prolapsed intussusception back through the anus could be performed in eight cases. In one case, it was impossible to push back the prolapsed bowel, and it was obligatory to resort to perineal resection of the intussusceptum by making a circumferential incision near its tip and by excision of the gangrenous segment. Right hemicolectomy was completed abdominally as usual.

Reduction by milking was tried in the other eight cases and succeeded in seven cases. Reduction by milking failed in one case with gangrenous terminal ileum, cecum, appendix, and ascending colon, and was treated by right hemicolectomy (Tables 2 and 3 ).

After milking, the intussusceptum was viable in five cases: in three of them, the intestine was healthy, in one case there were two ischemic perforations in the transverse and the descending colon, treated by resection and colocolic anastomosis, and in the other case the lumen of the terminal ileum was narrowed similar to a string and was treated by limited resection and ileoascending anastomosis.

The intussusceptum was gangrenous in two cases: one case without perforation and treated by right hemicolectomy and the other with three perforations, two in the ascending, transverse colon, treated by right hemicolectomy, and one perforation in the sigmoid colon exteriorized as a sigmoid colostomy.

\section{Operative complications}

Iatrogenic perforation, less than $1 / 2 \mathrm{~cm}$ in diameter, occurred in the terminal ileum and was repaired.

\section{Postoperative course}

Two patients were admitted in the intensive care unit for 2 days and 4 days. Postoperative diarrhea occurred for approximately 3 weeks in two cases and improved gradually on medical treatment. Three months postoperatively, one patient presented by a picture suggestive of adhesive
Table 2 Operative findings

\begin{tabular}{lc}
\hline Operative findings & Number of cases \\
\hline Viable intussusceptum & 5 \\
Gangernous intussusceptum & 4 \\
Intestnal perforation & 2 \\
Narrowed ileal lumen & 1 \\
\hline
\end{tabular}

Table 3 Operative procedures

\begin{tabular}{lc}
\hline Operative findings & Number of cases \\
\hline Milking without resection & 3 \\
Limited resection & 1 \\
Right hemicolectomy & 3 \\
Colectomy and colocoli anastomosis & 1 \\
Sigmoid colostomy & 1 \\
\hline
\end{tabular}

intestinal obstruction and did not respond to conservative treatment. Reexploration showed multiple intestinal bands treated by adhesiolysis.

\section{Discussion}

Intussusception is a common cause of bowel obstruction in childhood. In UK, the incidence is approximately two per 1000 live births [4]. There is a male preponderance and the typical age range is 6 months-2 years. More than $90 \%$ are ileocolic [5]. In our study, all the cases were in the typical age group and in all of them, the intussusception was ileocolic; however, there were six girls and three boys.

Prolapsed intussusception is a rare presentation in the developed world. Perhaps reflecting a longer duration of symptoms [5], Ngom et al. reported four cases.

Diagnosis of prolapsed intussusception can be made on a clinical basis although it might be misdiagnosed as simple rectal prolapse [5]. Two of our patients were referred to us diagnosed as rectal prolapse. Prolapsed intussusception is treated only surgically. The abdomen can be entered as in the classic cases of intussusception by a transverse right supraumbilical incision and the intussusception can be reduced to the abdomen easily. This occurred in six cases of our series; in one case, it was impossible to reduce the prolapse even with manipulating the intussusception by upward pressure through the perineum. As observed by Sivit [3], there were long mesentery and nonfixed right colon.

The intussusception mass may be viable or ischemic, and this depends on the length of the mesentery and the duration of symptoms. In our cases, the intussusceptum was viable in five cases and was gangrenous in nine cases with ischemic perforation of the intussuscepient in two cases and ischemia without perforation in two cases. All the nine patients have postoperative normal growth curve.

The current study highlight several features of prolapsed intussusception.

(1) It is a rare presentation of intussusception, usually due to delayed diagnosis.

(2) Its diagnosis is usually easy provided that a high index of suspicion is maintained. The diagnosis is solely based on clinical data.

(3) It may be misdiagnosed as rectal prolapse.

(4) The only possible definitive management option is surgical treatment. 
(5) Abdominal exploration can be performed by right transverse supraumbilical incision.

(6) Even after resection anastomosis up to extended right hemicolectomy, the prognosis is excellent without mortality.

\section{References}

1 Bisset GS III, Kirks DR. Intussusception in infants and children: diagnosis and therapy. Radiology 1988; 168:141-145.
2 Ngom G, Fall I, Sankale AA, Konate I, Sagna A, Ndoye M. Prolapsed intussusception in children: a report of 4 cases. Afr J Paediatr Surg 2005; 2:17-19.

3 Sivit CJ. Gastrointestinal emergencies in older infants and children. Radiol Clin North Am 1997; 35:865-877.

4 World Health Organization (WHO). Acute intussusception in infants and children. Incidence, clinical presentation and management: a global perspective. Geneva: World Health Organization (WHO); 2002. 2002WHO/V\&B/02.19.

5 Tennant S, Halliday K. Intussusception mimicking rectal prolapse. Pediatr Radiol 2008; 38:700-702. 